\title{
Hydatidose maligne: À propos d'un cas Malignant Hydatidosis: About a case
}

Bakkal $\mathrm{H}^{1 *}$, Benjelloun $\mathrm{H}^{2}$, Zaghba ${ }^{2}$, Yassine $\mathrm{N}^{3}$

${ }^{1}$ Resident in Pulmonology, Respiratory Diseases Service, CHU Ibn Rochd, 1 street des Hôpitaux 20360, Casablanca, Morocco

${ }^{2}$ Lung Professor, Department of Respiratory Diseases, CHU Ibn Rochd, 1 street des Hôpitaux 20360, Casablanca, Morocco

${ }^{3}$ Professor and Head of Respiratory Diseases Department, CHU Ibn Rochd, 1 street des Hôpitaux 20360, Casablanca, Morocco

DOI: $10.36347 /$ sjmcr.2020.v08i03.014

| Received: 22.02.2020 | Accepted: 04.03.2020 | Published: 13.03.2020

*Corresponding author: Bakkal $\mathrm{H}$

Abstract

Hydatidosis is a common zonoosis in farming countries, particularly in Morocco. pulmonary and hepatic localizations are the most noticed. Multivisceral thoracic, abdominal and pelvic dissemination is rare. It is a benign pathology whose management becomes difficult by its dissemination and its Localizations. We report a case report of a 54-yearold patient, operated 15 years ago for hepatic and epiploic hydatid cyst, showing out hemoptysis with hydatidoptysis and a distended abdomen. The chest X-ray revealed right hydroaeric feature. The thoraco-abdomino-pelvic CT scan underlined right pulmonary cystic formation as well as multiple hepatic, splenic, diffuse peritoneal, renal and pelvic cystic lesions. The hydatid serology was very positive. The therapeutic choice was based on medical treatment.

Keywords: Hydatid cyst, localizations, lung, management, prognosis.

Copyright @ 2020: This is an open-access article distributed under the terms of the Creative Commons Attribution license which permits unrestricted use, distribution, and reproduction in any medium for non-commercial use (NonCommercial, or CC-BY-NC) provided the original author and source are credited.

\section{INTRODUCTION}

Hydatidosis is an anthropozoonosis caused by larvae development of tapeworm in humans, Echinococcus granulosus [1]. Morocco, breeding country, is among the countries most infected with this parasitosis. Besides the hepatic and pulmonary localizations, which are the most frequent, hydatid cysts of pelvic, renal or peritoneal localization are among the rare cases. These lesions association remains rare or even exceptional [2]. Diagnosis is based on interrogation, imagery and serology. Hydatidosis is a benign pathology but can be serious by some of these localizations and its dissemination. We report a patient case with disseminated multiple hydatidosis associating pulmonary, hepatic, splenic, peritoneal and pelvic affection hospitalized in the pneumology department of the Casablanca University Hospital Center (CHU) in February 2018

\section{CASE RePORT}

54-year-old female patient, house wife, rural resident with dogs at home, and no similar cases in the family. She was operated for 15 years ago for hepatic and epiploic hydatid cyst. For the past 10 months, she had a purulent bronchial syndrome with low abundance hemoptysis and hydatidoptysis, together with dyspnea which worsened without chest pain. The overall was evolving in a context of apyrexia and a decline in the general condition. The clinical examination found out impaired general state, a polypnea at 26 cycles / min with orthopnea, a syndrome of mixed thoracic effusion at the level of the lower $2 / 3$ of the right hemithorax.

The abdomen was very distended with multiple masses of 3 to $6 \mathrm{~cm}$ of large ax, firm but painless, without inflammatory signs as far as protrusions at the level of the abdominal wall, some of which were well limited, recognized by the patient for four years and gradually increased in size "aspect simulating pregnancy at term" (Figure 1). The chest Xray showed a hydro-aerobic image of almost the entire right hemithorax with repression of the cardiac mass towards the contralateral side.

The thoraco-abdomino-pelvic CT scan had revealed a huge right pulmonary cyst, hepatosplenomegaly site of multiple cystic formations, some of which were calcified, right renal, peritoneal and pelvic localizations (Figure 3). From the first day of her admission, the patient had experienced several episodes of hydatidoptysis with membranes emission (Figure 4). She also had contractions and pelvic pain causing vaginally cysts emission. Biologicaly, the blood count found out hypochromic microcytic anemia at $11 \mathrm{~g}$ / dl without hyperleukocytosis with a slight eosinophilia 
at $490 / \mathrm{mm} 3$. The hydatic serology by indirect hemagglutinin (HAI) was very positive at $1 / 5120$. The cardiac ultrasound underlined an extrinsic compression aspect of the right atrial and the inferior vena cava without visible intracardiac cyst. The therapeutic management was based on hemostatic treatment and antiparasitic medical treatment based on Albendazole 10 to $15 \mathrm{mg} / \mathrm{kg}$ per day, 28-day cures spaced 15 days apart with education of the patient and her surrounding to a healthy lifestyle. However, the patient left the hospital refusing any therapy.

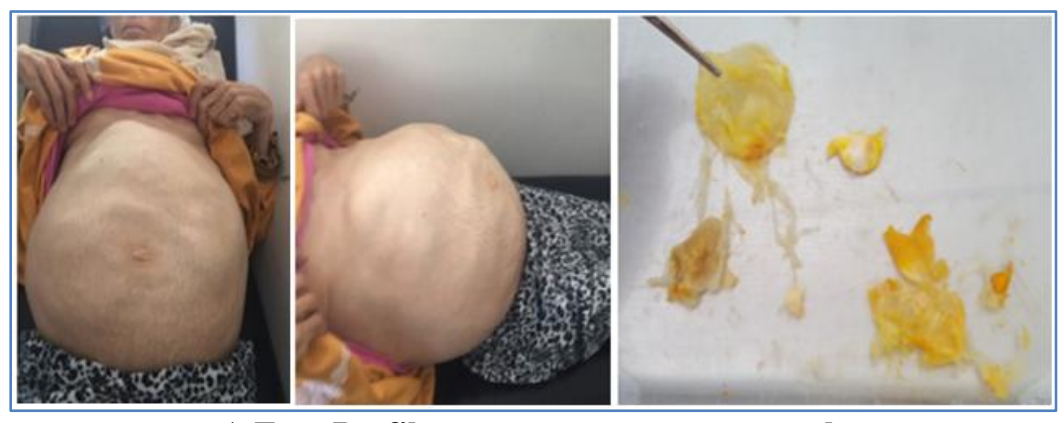

A Face Profil

b

Fig-I: a-Distended abdomen with multiple firm masses eve noticed b-Hydatidoptysis with membranes rejection

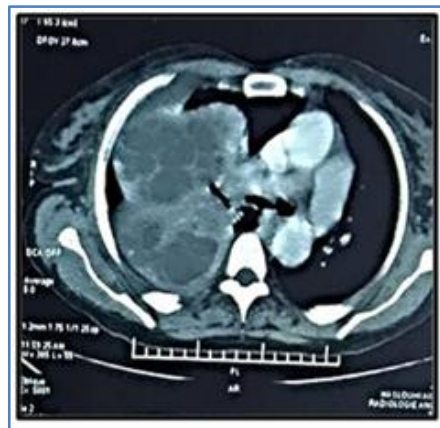

a

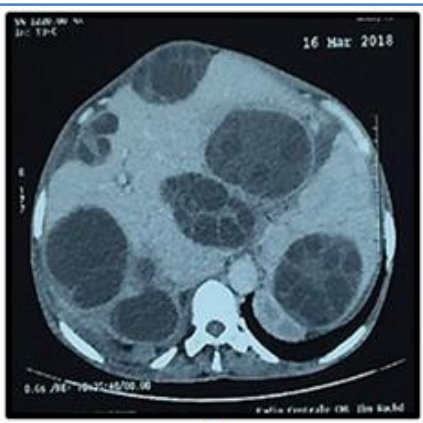

b

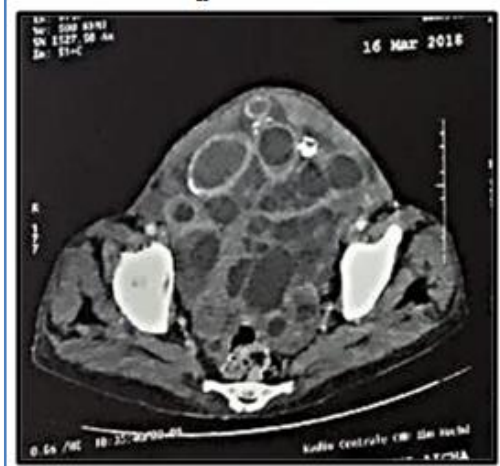

c

Fig-II: a-b-c: Thoraco-abdominopelvic CT scan showing multiple cysts a-pulmonary right b-hepatic, splenic and peritoneal c-pelvic

\section{DISCUSSION}

Human echinococcosis is a zoonosis caused by the organism's infestation with tapeworm larvae: Echinococcus granulosus (EG). Man becomes infected by accidental ingestion of the parasite's eggs, rejected excrements by host animals, by indirect contamination through contaminated food, water or soil, or by direct contact with these animals. The parasite cycle includes two hosts: a definit host (HD) and an intermediate host (HI). The classic cycle is the domestic cycle: dog (HD) - sheep (HI). Man accidentally receives the parasite cycle. Tapeworms of the genus Echinococcus, comes in 4 forms. The 2 main forms in humans are cystic echinococcosis and alveolar echinococcosis [1]. It has mainly reached young adults with a predominance of women $[2,3]$. Our patient was 54 years old.

Hydatidosis is cosmopolitan, prevalent in particular in the Mediterranean countries, North Africa, Latin America, Australia, New Zealand and Central Europe. The four countries reputed for their hydatic hyperendemicity are Uruguay (32/100 000), Argentina 
(21/100 000), Tunisia (15/100 000) and Morocco (7.2 / 100,000). However, the main focus of human hydatidosis is found in sub-Sahara Africa, in Kenya [1, 3].

Pulmonary affection is the second most frequent localization after that of the liver [1, 2, 3]. A study held in Turkey, where the prevalence of hydatid cyst is high, concerned 364 cases collected over eight years, the hepatic site was in the foreground in $69.8 \%$ of the cases, followed by the pulmonary site in $14.4 \%$ of the cases. The other localizations were only 1 to 6 cases each out of all the patients. The 27 cases of multiple hydatidosis collected in the same study were represented by the association of hepatic and peritoneal affection in $3 \%$ of the cases, hepatic and pulmonary in $2.2 \%$ of the cases; hepatic and splenic in $1.4 \%$ of the cases, hepatic and pelvic or hepatic and retroperitoneal affection in only $0.3 \%$ of the cases. Hence the rarity of affection associated with several organs [4].

Peritoneal hydatidosis is less frequent or even rare and is one of the most difficult complications to manage in hydatid disease since this affection is often generalized throughout the peritoneum in $2 / 3$ of the cases [5]. Its prevalence is $8 \%$ [5.3]. It is attested that peritoneal echinococcosis is most often secondary to the rupture or cracking of a hydatid cyst $(\mathrm{KH})$ of hepatic origin in 66 to $85 \%$ of the cases or of splenic origin in 10 to $20 \%$ of the cases $[5,6]$. In a series of 50 cases followed for peritoneal hydatidosis in the Maghreb, no case of primary peritoneal hydatid cyst was noted [6].

The association of a peritoneal and pulmonary hydatid cyst is rare; this is enhanced by several studies, mainly that carried out at the military hospital of Rabat, over 9 years, where no patient had a dual hydatid peritoneal and pulmonary localization [6].

Splenic affection is relatively rare and its incidence recently reported in studies is from 0.9 to $8 \%$. It is also reported that splenic hydatid cysts are generally solitary [7]. Our patient had multiple hydatid cysts at the splenic site.

The kidney is also a relatively rare site, representing 2 to $3 \%$ of all visceral sites. The right site is the most reported in the literature. The standard treatment for renal hydatid cyst is resection of the prominent dome or nephrectomy in case of a damaged kidney [8].

The incidence of pelvic hydatidosis is between 0.3 and $4.2 \%$ of hydatid localizations, $80 \%$ of which involve the genital area [2]. This affection has a slow and silent evolution with a late appearance of clinical signs like bladder irritation [2]. Our patient had pelvic pain without urinary signs, and emission of vaginal cysts with a normal speculum examination, related to uterine localization of the cysts.
In our pneumology department in Casablanca, over a period of 13 years, the extrathoracic localizations associated with pulmonary affection were peritoneal in two cases and pelvic in one case [9].

Although considered a benign pathology, hydatidosis can be serious and be grafted with a fairly high mortality in advanced forms or linked to postoperative recoveries. Its prognosis depends in particular on the extent of dissemination [5], within the same organ, mainly the lungs, or as a multi-organ; this was the case for our patient who witnessed a ruptured pulmonary hydatid cyst in the bronchi, associated with a very extensive multi-organ localization; hepatic, splenic, peritoneal, right renal and pelvic; either by some of its serious visceral localizations: cardiac, arterial. In fact, in our department, we have identified five cases of pulmonary multiple hydatic cysts, without extrathoracic affection, associated with cardiac, aortic, pulmonary artery cysts and mediastinal. An isolated mediastinal hydatid cyst was found in one case. Two of these patients died due to complications [10].

Diagnosis is based on the clinical context, the radiological aspect, the hydatid serology as well as the detection of scolex and membranes at the level of the bronchial aspiration fluid or rarely on an operating room [3]. Blood hypereosinophilia is found in 20 to $30 \%$ of the cases [3].

Radical treatment is mainly surgical. Albendazole is suggested as an adjunct to surgery, in inoperable forms or in case of surgery refusal.

Primary prevention remains the best way to reduce the incidence of this pathology. A prospect of a bovine vaccine to protect the host animals from this parasitosis seems to be in current development [1].

\section{Conclusion}

In the light of our clinical case, hydatidosis is a benign disease which becomes serious by its localizations and its complications. It remains a real public health problem in our country where farming is still traditional.

\section{REFERENCES}

1. Echinococcose. Organisationmondiale de la Santé 2019 (https://www.who.int/fr/news-room/factsheets/detail/echinococcosis).

2. Derfoufi O, Akwa EN, Elmaataoui A, Miss E, Esselmani H, Lyagoubi M. Profilépidémiologique de l'hydatidose au Maroc de 1980 à 2008.Ann Biol Clin. 2012; 70(4): 457-61.

3. Hydatidoseoukystehydatique, Actualités 2017.www. Medecinetropicale (mise à jour le07/12/2018).

4. Keser SH, Selek A, Ece D, Barişik CC, Şensu S, Geçmen GG. Review of hydatid cyst with focus on 
cases with unusual locations. Turk Patol Derg. 2017;33: 30-6.

5. Benamr S, Mohammadine E, Essadel E, Lahlou K, Taghy A, Chad B. L'hydatidose péritonéale secondaire mise au point à propos d'unesérie de 50 cas. Médecine du Maghreb. 2000; 82: 15-20.

6. El Mansari O, Zentar A, Sair K, Sakit F, Bounaim A, Janati IM. L'hydatidosepéritonéale. À propos de 12 cas. Annales de chirurgie. 2000.125( 4): 353357.

7. Lianos GD, Lazaros A, Vlachos K, Georgiou GK, Harissis HV, Mangano A and al. Unusual locations of hydatiddisease: a 33 year'sexperienceanalysis on 233 patients. Updates Surg. 2015;67(3):279-82.
8. Bentani N, Basraoui D, Wakrim B, Hiroual MR, CherifIdrissiGanouni N, Dahami Z. Kystehydatique du rein: aspects radiologiques et thérapeutiques. Progrès en urologie, 2012; 22 (16): 999-1003.

9. Morad S, Benjelloun H, Zaghba N, Bakhatar A,Yassine N, Bahlaoui A. Profilclinique et facteurspronostiques de l'hydatidosemultiviscérale (étude de 60 cas). Rev des Maladies Respiratoires. 2015; 32: A157-A158.

10. Zaghba N, Benjelloun H, Yassine N, Rochaidi Z, Bakhatar A. Bahlaoui A. Hydatidosemédiastinale : à propos de cinq cas. Rev des Maladies Respiratoires. 2009;26(HS1): 77. 